\title{
"It's not just what the doctor tells me:" Factors that influence surrogate decision-makers' perceptions of prognosis*
}

\author{
Elizabeth A. Boyd, PhD, Bernard Lo, MD, Leah R. Evans, Med, Grace Malvar, BA, Latifat \\ Apatira, BA, John M. Luce, MD, and Douglas B. White, MD, MAS \\ Department of Pharmacy Practice and Science (EAB), University of Arizona, Tucson, Arizona; \\ Program in Medical Ethics (BL), Department of Medicine, Division of Pulmonary and Critical Care \\ Medicine (LRE), Division of Pulmonary and Critical Care Medicine (GM), School of Medicine (LA), \\ University of California, San Francisco, San Francisco, California; Division of Pulmonary and \\ Critical Care Medicine (JML), San Francisco General Hospital, San Francisco, California; \\ Program on Ethics and Critical Care Medicine (DBW), Department of Critical Care Medicine; \\ University of Pittsburgh Medical Center, Pittsburgh, PA
}

\begin{abstract}
Objective-Physicians and surrogate decision-makers for seriously ill patients often have different views of patients' prognoses. We sought to understand what sources of knowledge surrogates rely on when estimating a patient's prognosis.
\end{abstract}

Design-Prospective, mixed-methods study using face-to-face, semistructured interviews with surrogate decision-makers.

Setting-Four intensive care units at the University of California, San Francisco Medical Center in 2006 to 2007.

Participants-Participants were 179 surrogate decision-makers for 142 incapacitated, critically ill patients at high risk for death.

Main Results-Less than 2\% (3 of 179) of surrogates reported that their beliefs about the patients' prognoses hinged exclusively on prognostic information provided to them by physicians. The majority cited other factors in addition to physicians' predictions that also contributed to their beliefs about the patients' prognoses, including perceptions of the patient's individual strength of character and will to live; the patient's unique history of illness and survival; the surrogate's own observations of the patient's physical appearance; the surrogate's belief that their presence at the bedside may improve the prognosis; and the surrogate's optimism, intuition, and faith. For some surrogates, these other sources of knowledge superseded the importance of the physician's prognostication. However, most surrogates endeavored to balance their own knowledge of the patient with physicians' biomedical knowledge.

Conclusions-Surrogates use diverse types of knowledge when estimating their loved ones' prognoses, including individualized attributes of the patient, such as their strength of character and life history, of which physicians may be unaware. Attention to these considerations may help clinicians identify and overcome disagreements about prognosis.

Copyright (9) 2010 by the Society of Critical Care Medicine and Lippincott Williams \& Wilkins

For information regarding this article: whitedb@upmc.edu.

The work was performed at the University of California, San Francisco.

The authors have not disclosed any potential conflicts of interest.

The study was reviewed and approved by the Committee on Human Research at the University of California, San Francisco. 
The majority of critically ill patients in intensive care units (ICUs) depend on surrogate decision-makers to make end-of-life decisions on their behalf $(1,2)$. To make informed choices, surrogates must have a clear understanding of the patient's diagnosis and likely prognosis. Despite the difficulty of these decisions and the ambivalence that many surrogate decision-makers report (3), most surrogates wish to participate actively in treatment decisions (4), view communication with physicians as one of the most important aspects of critical care (5-7), and desire timely, honest discussions about prognosis with their loved one's physician (2).

The complexities of physicians' prognostication have been well-described, most extensively by Christakis (8). Previous research suggests that physicians typically base their prognostic estimates on previous experience caring for patients with similar disease, population-based survival estimates, and the physiologic status of the patient (9-11). Other research has identified social interactional factors and physician attributes that may affect physicians' prognostications $(8,12)$. Physicians view the task of prognostication as one of the most difficult aspects of medicine (8).

Although a number of studies have documented that surrogates' estimates of prognosis are often at odds with the physician's prognostic estimates $(13,14)$, comparatively little is known about how surrogates arrive at an understanding of the patient's prognosis. Most commentators have postulated that poor communication is the cause of physician-surrogate discordance over prognosis $(8,15,16)$. Our clinical experience has been that even with excellent communication, there sometimes remains a gap between the physician and surrogate about a patient's prognosis. This raises the possibility that physicians and surrogates may systematically differ in how they formulate prognostic estimates. It is crucial to understand this element of surrogate decision-making if we are to move forward in improving decision-making for critically ill patients. Therefore, we conducted semistructured interviews with surrogates of critically ill patients to determine how they arrive at their assessment of a patient's prognosis.

\section{SUBJECTS AND METHODS}

We conducted this mixed-methods study of surrogate estimates of patient prognosis between January 2006 and October 2007. We conducted 179 semistructured interviews with the surrogate decision-makers for a prospectively defined cohort of incapacitated, critically ill patients in four ICUs at the University of California, San Francisco Medical Center. The ICUs included two medical-surgical units, a neurologic unit, and a cardiac unit. Patients were eligible if they were older than 18 yrs of age, experienced respiratory failure requiring mechanical ventilation, lacked decision-making capacity, and had an Acute Physiology and Chronic Health Evaluation II score of $>25$ (predicting in-hospital mortality of $>40 \%$ ). Decision-making capacity was assessed by the patient's attending physician; the Acute Physiology and Chronic Health Evaluation II score was calculated by one of the authors (GM).

Participants were eligible for the study if they were at least 18 yrs of age, spoke and understood English without the aid of a translator, and self-identified as a surrogate decision-maker for the patient. If the responsibility for surrogate decision-making was shared among family members, then we enrolled up to three per patient who reported having the most responsibility. This approach allowed a range of participants in the interviews but allowed for efficiency in conducting the interviews. We identified eligible surrogates by screening daily in each ICU. Before approaching family members, we obtained permission from the patient's attending physician. Seventy-nine percent of surrogates reported having spoken with their patient's attending physician about prognosis before being approached by 
the interviewer. No investigator served as the attending physician for any patient. All participants provided written consent to participate in the study. The study was approved by the Committee on Human Research at the University of California, San Francisco.

All interviews with surrogates took place between days 3 and 5 of the patient's mechanical ventilation. Participants were first asked to complete a demographic questionnaire that asked for a percentage estimate of their loved one's chances of surviving the hospitalization. After the completion of this questionnaire, a member of the study staff (GM) met with the surrogate for a private, semistructured interview conducted in a quiet conference room near the ICU. The interviewer used principles of cognitive interviewing (17) to conduct the interviews, including using nondirected, open-ended questions and general follow-up prompts, and probing for the reasons behind subjects' responses. Interview length ranged from 2 to 39 mins, with most lasting approximately 15-20 mins.

The interview began after participants had provided written estimates of what they thought their loved one's chances of survival were. Each participant was asked the following question: "I see that you've noted here that you think your loved one has a(n) _ \% chance of surviving the hospitalization. Can you tell me a little bit about what has made you think this is his/her prognosis?" The interviewer pursued themes as they arose with follow-up questions such as, "can you say more about why you think this is their chance?" The interviewer did not volunteer topics or suggest areas for the interviewee to consider.

Interviews were audio-taped and transcribed verbatim by a medical transcriptionist. Codes to describe subjects' responses were developed inductively and iteratively, with at least four members of the research team participating in all stages of the coding and analysis. We first coded a subsample of 11 interviews line-by-line to characterize emergent themes. We subsequently refined these themes by comparing and combining conceptually similar themes until we reached theoretical saturation, with no new themes emerging. After all investigators agreed on the preliminary coding framework, two coders coded the full data set. We used ATLAS.ti software (Berlin, Germany) for management of the qualitative data. Any new themes not appearing in our initial coding scheme were added as they were encountered.

To assess intercoder reliability, we calculated a kappa statistic on a random sample of $20 \%$ of the coded transcripts. The average kappa statistic was 0.86 (range, 0.71-1.00). A kappa value $>0.8$ represents excellent inter-rater reliability (18). To ensure a diverse perspective on our data, we used a multidisciplinary team to develop the coding framework, including investigators with expertise in critical care medicine, bioethics, sociology, general internal medicine, doctor-patient communication, and end-of-life care. We also presented the preliminary conceptual framework to a sample of study participants for confirmation and/or modification, which is a process known as member checking (19).

\section{RESULTS}

Among 183 eligible patients identified for the study, the surrogates of $19(10 \%)$ were not approached at the request of the attending physician and $22(12 \%)$ of the surrogates declined to participate. In total, 142 (78\%) patients had surrogates who participated in the study, with a total of 179 surrogates enrolled.

The demographic characteristics of the surrogates and patients are shown in the Table 1. The sample was diverse in terms of gender, race/ethnicity, religious affiliation, and education level. Patients' mean Acute Physiology and Chronic Health Evaluation II score at the time of enrollment was $30 \pm 4$. Overall, $45 \%$ (64 of 142) of patients died during the hospitalization. In response to the question regarding the chances that the loved on would 
survive the hospitalization, surrogates' mean prognostic estimate was 69\% (SD, 29.6; range, $2 \%$ to $100 \%$ ).

Two percent ( 3 of 179) of surrogates reported basing their view of the patient's prognosis solely on the physician's prognostic estimate; almost half of the interviewed surrogates (47\%) reported basing at least part of their own prognostic estimates on prognostications and information given to them by a physician. The form and specificity of that information varied. In some instances, surrogates reported hearing direct pronouncements about the likely course of their loved one's illness. For example, one surrogate reported, "Yeah, he told me that the prognosis was not good and most patients who are transplant patients, usually, when they get this kind of infection, they usually do not survive, is what he told me." Others reported specific numerical estimates, as in the following example. "Basically, what we've been told by the doctors is that the aspergillus fungal infection that she has a $90 \%$ mortality rate. And when I look at, you know, what her chances of survival are, I'm looking at that $10 \%$.... I mean, they will not just come out and say, 'I think she has a 10\% chance of surviving.' You know, they're not going to say that. But what they say is, 'This infection has a $90 \%$ mortality rate.' And that's what they said."

More commonly, however, surrogates reported going through an inferential process to arrive at a prognosis, working from less specific information or a sense of how the physician felt about the patient's chances. For example, one surrogate explained that the doctors avoided putting specific numbers on her loved one's chances. "You know, only one doctor has really kind of given us a percentage. She said it's really tough and said it was.... I go, 'Is this day by day?' and she's like, 'No, this is hour by hour.' And, 'what are the chances?' And she said, 'Fifty percent.' But you know, most of the doctors are talking very clinically about little steps here, little steps there, and if we can kinda move in that direction, then things' 11 be good. But you know, they're not really giving you — giving us percentages, you know?"

Others pointed to the doctors' words as providing only broad estimates but nothing specific. "They had just said that it's not good (5-sec silence) ... But they did not say that it was impossible. They just said that it wasn't—-the chances weren't great, that she was critical."

Most surrogates cited at least one other factor that informed their beliefs about the patient's prognosis. We identified five other main sources that contributed to surrogates' estimations of the patient's prognosis: 1) patient's unique intrinsic qualities and will to live; 2) interpretations of the patient's physical appearance or status; 3 ) the patient's history of illness and/or survival; 4) surrogates' beliefs in the power of their bedside presence; and 5) optimism, intuition, and faith. We provide examples of each of these factors in detail.

\section{Patient's Intrinsic Qualities and Will to Live}

Twenty-seven percent (49 of 179) of surrogates believed that certain unique attributes of the patient predicted their likelihood of survival. Having a "stubborn" or "determined" disposition and being stronger than most people were key factors for some surrogates. One husband said, "I chose the high number because, basically, I know that my wife is a fighter beyond the normal person." Another described the patient as “... just a strong person. She's ... I do not know, she just ... That's her personality. She doesn't give up much.... I just know she has really strong will." Similarly, there were some family members (10 of 179; $5.5 \%$ ) who pointed to their loved one's fading fortitude to explain their belief about her poor prognosis. One family member said, "I do not know if my aunt has the fight left in her."

\section{Interpretations of the Patient's Physical Appearance or Status}

Some surrogates relied on their own observations of the patient's physical appearance to inform their belief about the patient's prognosis. Sixty-four percent (114 of 179) mentioned 
their personal observation of the patient's physical appearance as one source of information. Surrogates noted such aspects of the patient's appearance as facial expression, hue of the skin, apparent comfort or discomfort, and degree of synchrony with the ventilator. Temporal changes (or the lack thereof) in the patient's appearance also were given prognostic significance. The following example exemplifies both aspects of this: "He just looks really, really sick. He doesn't show any improvement from day to day. I mean, the first day, you know you figure, well, he's gonna be really sick, but the second day, you think, well maybe he'll be a little bit better. Well each day it's like he's just staying the same. So, you kinda get discouraged when you do not see any improvement."

Likewise, a patient who looked better or seemed more active was understood as having a better prognosis. "I think he has $90 \%$ because - because today in the morning, he opened one of his eyes when we were talking to him. And it seems like, when we go in there and talk to him, he kind of gets a little desperate for him to- he wants-like he wants to talk to us."

The patient's previous physical fitness and age were also used as indicators of prognosis, according to $37 \%$ (67 of 179) of family members. For instance, as one family member noted, 'And he's- before this one illness, he's never really been hospitalized before, he's always been very healthy. And he's athletic and strong and participates in a pretty good exercise program, before this illness." Similarly, being relatively young was often seen as an indicator of a good prognosis. "And she's a young woman. She's only 57." Physical status and age also combined to influence prognostic estimates. "Well, I think if he were $10 \mathrm{yrs}$ younger, his body would be stronger. Ten years ago, he was in pretty good shape. So I think that he would not have been as likely to have gotten the pneumonia, the way he did."

\section{Knowledge of the Patient's History of Illness and/or Survival}

Many surrogates relied on their personal knowledge of unique attributes of the patient to inform their prognostic estimates ( 51 of $179 ; 28 \%$ ), such as the patient's history of illness and previous survival in the face of severe illness. This was particularly so for surrogates who perceived an optimistic outcome for their loved one. As one remarked, "He beat cancer so I feel very strongly that he can beat this pneumonia." Similarly, another family member noted, "But it's kind of interesting because she's been in this situation, very similar, many times and she's somehow defied the odds."

As these comments suggest, surrogates' use of other sources to inform their own prognostic estimates were rarely straightforward applications of statistical likelihood or simple "facts", Rather, surrogates' views were shaped by an understanding of the unique attributes of the patient that may not be accessible to physicians. These types of beliefs and understandings may differ from the clinical experience and population-based evidence that the physician may bring to the discussion.

\section{Power of the Bedside Presence}

The belief that one's presence and support could improve the patient's prognosis was discussed by $13 \%$ (24 of 179) of surrogates. Through their own positive thinking and support, these surrogates believed that they could improve the patient's prognosis. As one explained, "Well, I think a lot of his surviving has been with the help of myself and my daughter. Not just the doctors and medicine, but the fact that we've been by his side, whenever we possibly can, and we have been talking in his ear, yelling in his ear, telling him to think positive. When he was jaundiced and in a coma, I kept saying, 'Think pink,' because he was so yellow and so sick. And I said, 'You can do it. Mind over matter,' you 
know, 'The brain is powerful' and, 'Do not give up' and, 'You've gotta fight. You've gotta fight.... I want to bring you home.' And I think that really helped him a lot."

Others $(5 \%$; 9 of 179$)$ reported that rallying the community of family and friends could also change the prognosis. The support of family and friends, support groups, and church groups were all mentioned as sources of optimism that tilted a prognosis more favorably. As one surrogate described, "So when we go in there and talk to him, we always say encouraging things and to keep fighting, because there's that chance that he can make it through." Similarly, another family member noted, "Because then it allows him to know that we're here for him and that he's more encouraged to fight, when he knows we're there." A few described the relationship as direct and causal: "I mean, the nuns came over here, with the priest, and they anointed the sick. And a couple of days later, she was okay."

\section{Optimism, Intuition, and Faith-Based Beliefs}

Thirty-six percent (65 of 179) of surrogates used their own intrinsic optimism or pessimism. This "power of positive thinking" was strong and pervasive and seemed important to maintain even in the face of other evidence, such as physician's prognostic estimates or how the patient physically appeared to be doing. As one family member said, "Because we want to be optimistic. I mean, we want to be positive. So that's why we're saying he's going to have $90 \%$ of a chance to survive. We do not want to be negative." For some, allowing themselves to think that their loved on will die was unacceptable. "It means that he will. That he'll survive. And I do not want to think that he will not."

Similarly, 4\% (8 of 179) of surrogates based their estimates in their own pessimistic view of what will happen. For some, this was reported to be "just the way they see things," sometimes despite the information from physicians. As one surrogate said, "I see that the chance of survival is slim, no matter what the doctors say."

Nineteen percent (34 of 179) cited reliance on intuition or "gut feeling" to inform one's estimates. Intuition informed both positive and negative estimates and seemed to mitigateor even negate - any information to the contrary. Surrogates reported "just knowing" or having a strong sense that their loved one would survive, despite what the doctors said, as this family member explained, in light of a 50-50 estimate from the physician, "But in my heart, I think there's more than a fifty chance that the doctors are giving us."

For 20\% (35 of 179) of surrogates, a faith in God overrode any other source of prognostic information, allowing the person to believe, against all odds, that their patient was going to survive. This faith was expressed as a belief in the power of prayer, in the power of prayer circles and community support for the patient, or as the presence of God working through the actions of the doctors, nurses, and hospital staff. Some surrogates believed that it was not only their faith but also the patient's faith that would carry them toward recovery and health. As one parent described, "My daughter is very, very sick, but I believe her faith in God and her faith in being cured of this rare disease she has will - has given her strength to survive and to-to live."

Two percent (4 of 179) reported a belief in the power of reciprocity, believing that their loved ones' good behavior, kind actions, or helpful life work would result in a "favor" being given back from the universe. Some reported that their loved ones gave freely of their time to other sick people, that they used their humor or abilities to help others, and that this would somehow return to help them through their own struggles. As one family member said, "Good things come to good people so I'm gonna hope that-you know, call in some markers for his good behavior." 
Finally, in light of terrible odds and the realization that the patient was not going to recover, this expression of faith was termed as a belief in - or hope for-miracles. When they had little else on which to base an optimistic prognosis, $4 \%$ (7 of 179) of surrogates said they resorted to hoping for a miracle. "So the only thing we have left is a miracle. And before this, I really do not think I would have believed in miracles."

\section{DISCUSSION}

Our findings suggest that very few surrogate decision-makers rely exclusively on physicians' prognostications to form their perception of the patient's prognosis. Instead, most weigh the physician's clinical judgment against their own knowledge of the internal character and life history of the patient, their own observations of the patient, as well as their own belief in the power of their support and presence, and optimism, intuition, and faith. Understanding that factors other than physicians' prognostication may inform surrogates' prognostic estimates may help physicians address conflicts about prognosis that arise with surrogates.

Our data, documenting the varied sources of "knowing" used by surrogates, underscore what Kaufman has described as the "incommensurability of lay and medical worlds, words, and understandings" (20). Surrogates' beliefs about prognosis appear to be ultimately shaped by a very personal assessment of who the patient is, what the patient's life has entailed, and how their own actions and understandings may impact the patient's prognostic outcome.

These findings suggest that surrogates' prognostications are rooted in complex systems of interpretation, belief, experience, and evidence that may differ from the conventional understanding of how physicians formulate prognostic estimates. Specifically, previous research suggests that physicians in ICUs rely on previous experiences with patients with similar physiologic illnesses and population-based outcome data (12). A conventional approach to discussing prognosis in terms of outcomes of populations of "similar" patients may fall short if physicians do not also recognize and appreciate that surrogates also view unique attributes of the patient as relevant to their prognosis.

Understanding the diverse sources of knowledge on which surrogates draw may help physicians better-understand and address conflicts that may emerge over patients' prognosis. For example, identifying that a surrogate is misinterpreting the significance of a patient's movements and physical appearance may allow a more meaningful dialogue about the prognostic significance - if any — of the physical signs. Understanding that a family member believes the patient is mentally or physically stronger than the "average" patient may help shift the physicians away from a belief that "the family just doesn't get it" and toward an appreciation of the different sources of knowledge the family is incorporating into their considerations of prognosis.

Our study has several limitations. First, because we interviewed surrogates between 3 and 5 days of mechanical ventilation, we cannot determine whether surrogates' views persisted over days or weeks of illness. It is possible that the views expressed relatively early in the patient's hospitalization tended to discount physicians' estimates in favor of a more optimistic view. However, even if surrogates' views change over time, physicians must contend with surrogates' perceptions in real time. Previous research suggests that surrogates may expect their views to change over time and that they require time to prepare emotionally and practically for a loved one's death $(21,22)$. Understanding what factors contribute to surrogates' understanding over the course of the patient's hospitalization may assist physicians in their efforts to help surrogates make critical decisions in the ICU. 
Second, because the design of the study was intended to give voice to surrogates' perspectives on prognosis, we cannot determine whether or how wishful thinking, denial, hope, or other psychological factors might be at work in surrogates' accounts of their views on their loved ones' prognosis. Given our use of interviews to elicit surrogates' views, we would not expect to be able to distinguish between denial and "real" estimates. Physicians, however, are in the same situation, relying only on what surrogates may tell them or show them through their actions and reactions. Understanding that factors other than what the doctor has told them—such as hope, optimism, or a belief in miracles (23)—are critical pieces of a surrogate's perspective on a loved one's prognosis may helpfully inform physicians' discussions throughout the decision-making process.

Finally, our interview was designed to give surrogates maximum flexibility in addressing why they arrived at the specific prognostic estimate they reported in the questionnaire. We did not ask them to rank order or establish a hierarchy of information. Thus, we cannot address how surrogates balance each source of information in arriving at their estimations.

\section{CONCLUSIONS}

Our findings may raise the question of whether some surrogates' tendencies not to incorporate the physicians' prognostic estimates constitute an obstacle to autonomous decision-making. Our general view is that, just as it is problematic for physicians to wholly disregard the surrogate's perspective, so too is it problematic for surrogates to wholly disregard the physician's professional judgment. There is strong evidence showing that physicians are accurate predictors of mortality in the ICU and are as accurate as Acute Physiology and Chronic Health Evaluation II scores $(15,24,25)$. We believe that both parties have important insight and expertise to add to a richer understanding of the patient. We propose that the goal should be to view prognostication not as a unidirectional transmission of knowledge but rather a bidirectional discussion aimed at achieving a shared understanding of not only the patient's physical condition but also the unique life experience and personal characteristics that many surrogates view as relevant to predicting the patient's future.

\section{Acknowledgments}

This project was supported by a U.S. National Institutes of Health grant KL2 RR024130 from the National Center for Research Resources (NCRR), a component of the NIH Roadmap for Medical Research (DBW).

\section{References}

1. Prendergast TJ, Claessens MT, Luce JM. A national survey of end-of-life care for critically ill patients. Am J Respir Crit Care Med. 1998; 158:1163-1167. [PubMed: 9769276]

2. LeClaire MM, Oakes JM, Weinert CR. Communication of prognostic information for critically ill patients. Chest. 2005; 128:1728-1735. [PubMed: 16162781]

3. Cherlin E, Fried T, Prigerson HG, et al. Communication between physicians and family caregivers about care at the end of life: When do discussions occur and what is said? J Palliative Med. 2005; 8:1176-1185.

4. Heyland DK, Tranmer J, O'Callaghan CJ, et al. The seriously ill hospitalized patient: Preferred role in end of life decision-making? J Crit Care. 2003; 18:3-10. [PubMed: 12640606]

5. Hanson LM, Danis M, Garrett J. What is wrong with end-of-life care? Opinions of bereaved family members. J Am Geriatric Society. 1997; 45:1339-1344.

6. Baker R, Wu A, Teno J, et al. Family satisfaction with end-of-life care in seriously ill hospitalized adults. J Am Geriatric Society. 2000; 48:S61-S69.

7. Teno JM, Claridge BR, Casey V, et al. Family perspectives on end of life care at the last place of care. JAMA. 2004; 291:88-93. [PubMed: 14709580] 
8. Christakis, NA. Death Foretold: Prophecy and Prognosis in Medical Care. Chicago, IL: The University of Chicago Press; 1999.

9. Lamont EB, Christakis NA. Complexities in prognostication in advanced cancer: "To help them live their lives the way they want to. JAMA. 2003; 290:98-104. [PubMed: 12837717]

10. Teno JM, Fisher E, Hamel MB. Decision-making and outcomes of prolonged ICU stays in seriously ill patients. J Am Geriatr Soc. 2000; 48(5 Suppl):S70-S74. [PubMed: 10809459]

11. Azoulay E, Chevret S, Leleu G. Half the families of intensive care unit patients experience inadequate communication with physicians. Crit Care Med. 2000; 28:3044-3049. [PubMed: 10966293]

12. Anspach, RR. Deciding Who Lives: Fateful Choices in the Intensive Care Nursery. Berkeley, CA: University of California Press; 1997.

13. Weeks JC, Cook EF, O'Day SJ. Relationship between cancer patients' predictions of prognosis and their treatment preferences. JAMA. 1998; 279:1709-1714. [PubMed: 9624023]

14. White DB, Engelberg RA, Wenrich MD, et al. Prognostication during physician-family discussions about limiting life support in intensive care units. Crit Care Med. 2007; 35:1-7.

15. Lee SJ, Fairclough D, Antin JH, et al. Discrepancies between patient and physician estimated for the success of stem cell transplantation. JAMA. 2001; 285:1034-1038. [PubMed: 11209174]

16. Fried TR, Bradley EH, O'Leary J. Prognosis communication in serious illness: Perceptions of older patients, caregivers, and clinicians. J Am Geriatr Soc. 2003; 51:1398-1403. [PubMed: 14511159]

17. DeMaio, TJ. Cognitive Interviewing Techniques: In the Lab and in the Field. San Francisco, CA: Jossey-Bass; 1996.

18. Sackett, DL.; Haynes, R.; Guyatt, GH., et al. Clinical Epidemiology: A Basic Science for Clinica Medicine. 2. Boston, MA: Little, Brown and Company; 1991.

19. Giacomini MK, Cook DJ. Users' guides to the medical literature: XXIII. Qualitative research in health care: Are the results of the study valid? JAMA. 2000; 284:357-362. [PubMed: 10891968]

20. Kaufman, SR. And a Time to Die: How American Hospitals Shape the End of Life. New York, NY: A Lisa Drew Book/Scribner; 2005.

21. Chambers-Evans J, Carnevale FA. Dawning of awareness: The experience of surrogate decision making at the end of life. J Clin Ethics. 2005; 16:28- 45. [PubMed: 15915844]

22. Evans LR, Boyd EA, Malvar G, et al. Surrogate decision-makers' perspectives on discussing prognosis in the face of uncertainty. Am J Respir Crit Care Med. 2009; 179:48-53. [PubMed: 18931332]

23. Jacobs LM, Burns K, Jacobs BB. Trauma death: Views of the public and trauma professionals on death and dying from injuries. Arch Surg. 2008; 143:730-735. [PubMed: 18711031]

24. Kruse JA, Thill-Baharozoan MC, Carlson RW. Comparison of clinical assessment with APACHE II for predicting mortality risk in patients admitted to a medical intensive care unit. JAMA. 1988; 260:1739-1742. [PubMed: 3137374]

25. Rocker G, Cook D, Sjokvist P, et al. Level of care study investigators: Canadian critical care trials group. Crit Care Med. 2004; 32:1149-1154. [PubMed: 15190965] 
Table 1

Demographic characteristics of patients and surrogate decision-makers ${ }^{a}$

\begin{tabular}{|c|c|}
\hline Characteristic & Total, n (\%) \\
\hline Patients & $142(100)$ \\
\hline \multicolumn{2}{|l|}{ Gender } \\
\hline Male & $78(55)$ \\
\hline Mean age (SD) & $59(18.2)$ \\
\hline \multicolumn{2}{|l|}{ Race/ethnicity $b$} \\
\hline White & $83(58)$ \\
\hline Asian/Pacific Islander & $30(21)$ \\
\hline Hispanic & $17(12)$ \\
\hline Black & $14(10)$ \\
\hline Native American & $2(1)$ \\
\hline Other/multiethnic/undocumented & $3(2)$ \\
\hline \multicolumn{2}{|l|}{ Admission diagnosis } \\
\hline Neurologic failure & $40(28)$ \\
\hline Respiratory failure & $38(27)$ \\
\hline Cardiac failure/shock (includes sepsis) & $34(24)$ \\
\hline Gastrointestinal failure (includes pancreatitis) & $11(8)$ \\
\hline Hepatic failure & $11(8)$ \\
\hline Metastatic cancer & $5(4)$ \\
\hline Renal failure & $3(2)$ \\
\hline Mortality & $64(45)$ \\
\hline Mean Acute Physiology and Chronic Health Evaluation II score, mean (SD) & $30(4)$ \\
\hline Surrogate decision-makers & $179(100)$ \\
\hline \multicolumn{2}{|l|}{ Gender } \\
\hline Female & $125(70)$ \\
\hline Mean age (SD) & $47(14.8)$ \\
\hline \multicolumn{2}{|l|}{ Race/ethnicity $b$} \\
\hline White & $109(61)$ \\
\hline Asian/Pacific Islander & $28(16)$ \\
\hline Hispanic & $26(15)$ \\
\hline Black & $19(11)$ \\
\hline Native American & $2(1)$ \\
\hline Other/multiethnic/undocumented & $12(7)$ \\
\hline \multicolumn{2}{|l|}{ Relationship to patient } \\
\hline Child & $66(37)$ \\
\hline Spouse/partner & $39(22)$ \\
\hline Other & $31(17)$ \\
\hline Sibling & $23(13)$ \\
\hline Parent & $18(10)$ \\
\hline
\end{tabular}




\begin{tabular}{|c|c|}
\hline Characteristic & Total, n (\%) \\
\hline Friend & $2(1)$ \\
\hline \multicolumn{2}{|l|}{ Level of education } \\
\hline Graduate or professional school & $38(21)$ \\
\hline 4-yr college degree & $35(20)$ \\
\hline Some college or trade school & $58(32)$ \\
\hline Some high school (including diploma or general education development) & $48(27)$ \\
\hline 8 th grade or less & $0(0)$ \\
\hline \multicolumn{2}{|l|}{ Primary language } \\
\hline English & $145(81)$ \\
\hline Spanish & $13(7)$ \\
\hline Tagalog & $6(3)$ \\
\hline Cantonese & $5(3)$ \\
\hline Other ${ }^{c}$ & $10(6)$ \\
\hline \multicolumn{2}{|l|}{ Religious preference } \\
\hline Catholic & $57(32)$ \\
\hline None/agnostic/atheist & $38(21)$ \\
\hline Protestant & $37(21)$ \\
\hline Other Christian (Latter Day Saints/Mormons, Jehovah's Witnesses) & $24(13)$ \\
\hline Did not respond & $12(7)$ \\
\hline Jewish & $5(3)$ \\
\hline Other (including Spiritualist) & $3(1.5)$ \\
\hline Hindu & $1(0.5)$ \\
\hline Buddhist & $1(0.5)$ \\
\hline Muslim & $1(0.5)$ \\
\hline \multicolumn{2}{|l|}{ Importance of religion/spiritual beliefs in everyday life } \\
\hline Very important & $86(48)$ \\
\hline Fairly important & $38(21)$ \\
\hline Not too important & $30(17)$ \\
\hline Not at all important & $12(7)$ \\
\hline Declined to respond & $13(7)$ \\
\hline \multicolumn{2}{|l|}{ Self-reported discussion of prognosis with doctor before interview } \\
\hline Yes & $142(79)$ \\
\hline
\end{tabular}

\footnotetext{
${ }^{a}$ Values are reported as numbers (percentages) unless otherwise indicated;

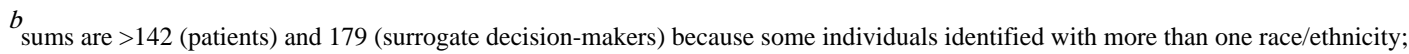

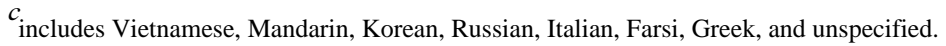

